PontIFícIA UNIVERSIDADE CATÓLICA dO RIO DE JANEIRO

\title{
A Importância da Gestão Financeira na Micro \\ e Pequena Empresa \\ Estudo de Caso de uma Empresa de \\ Refrigeração
}

\section{Abraão Ribeiro Pinto}

Trabalho de Conclusão de Curso

Centro de Ciências Socials - CCS

DEPARTAMENTO DE AdMINISTRAÇÃO

Graduação em Administração de Empresas 


\section{Abraão Ribeiro Pinto}

\section{A Importância da Gestão Financeira na Micro e Pequena Empresa}

Estudo de Caso de uma Empresa de Refrigeração

Trabalho de Conclusão de Curso

Trabalho de Conclusão de Curso, apresentado ao programa de graduação em Administração da PUC-Rio como requisito parcial para a obtenção do titulo de graduação em Administração.

Orientador: André Cabús Klötzle

Rio de Janeiro 


\section{Resumo}

Pinto, Abraão Ribeiro. A Importância da Gestão Financeira na Micro e Pequena Empresa. Estudo de Caso de uma Empresa de Refrigeração. Rio de Janeiro, 2017. 30 p. Trabalho de Conclusão de Curso - Departamento de Administração. Pontifícia Universidade Católica do Rio de Janeiro.

O presente trabalho propõe demonstrar a importância da gestão financeira para as micro e pequenas empresas e como este conhecimento pode gerar uma visão estratégica, demonstrando a eficácia desta ferramenta, que visa trazer segurança na tomada de decisão, e permitindo que alcancem a perenidade do negócio em um mercado cada vez mais competitivo. A abordagem é realizada na Empresa UCL Refrigeração Ltda., situada no município do Rio de Janeiro - RJ, que atua no setor de manutenção e instalação de arescondicionados.

Palavras-chave

Gestão Financeira, Pequenas e Médias Empresas

\section{Abstract}

Pinto, Abraão Ribeiro. The Importance of Financial Management in Micro and Small Enterprises. A Case Study of a Refrigeration Company. Rio de Janeiro, 2017. 30 p. Trabalho de Conclusão de Curso - Departamento de Administração. Pontifícia Universidade Católica do Rio de Janeiro.

This work proposes to demonstrate the importance of financial management for micro and small companies and how this knowledge can generate a strategic vision, demonstrating the effectiveness of this tool that aims to bring security in decision making, allowing them to reach the perenniality of the business in a market ever more competitive. The approach is carried out at Empresa UCL Refrigeração Ltda., located in the city of Rio de Janeiro - RJ, which operates in the maintenance and installation of air conditioners.

\section{Key-words}

Financial Management, Small and Middle Enterprises 


\section{Agradecimentos}

A Deus Pai, protetor, companheiro e amigo. A minha filha Beatriz, que nunca deixou de acreditar que eu poderia concretizar tal feito e também meu afilhado Leonardo. As minhas irmãs Lena, Gaeth e Nice que me ampararam nos momentos mais difíceis dessa jornada. Aos meus amigos, em especial meu amigo Vagner Pessanha por todo o suporte e amparo concedido, juntamente com Simone que esteve presente em grande parte nesta parceria. Aos meus professores que foram a base para esta conquista com especial menção ao meu mestre amado Sergio Nóbrega, que sempre me incentivou a não desistir nos momentos mais sombrios, e do meu orientador Professor André Klötzle que monitorou e acompanhou a concretização deste trabalho e finalmente a Pontifícia Universidade Católica do Rio de Janeiro, instituição que me ofertou a oportunidade de galgar estes degraus até o patamar almejado. 


\section{Sumário}

1. Introdução 1

2. Referencial Teórico 8

$\begin{array}{lr}\text { 3. Metodologia } & 16\end{array}$

4. Apresentação e Anãlise dos Resultados 20

5. Conclusões 27

$\begin{array}{lr}\text { Referências Bibliográficas } & 29\end{array}$ 


\section{Introdução}

Nas últimas décadas, houve um expressivo crescimento das micro e pequenas empresas no Brasil. Este aumento tem grande influência na economia, na forma de geração de renda e novas oportunidades para uma crescente população economicamente ativa do país. Contudo, é notório que a inexistência de um planejamento e uma boa gestão financeira, pilares para quaisquer negócios, nem sempre é levada em consideração na administração dessas empresas, o que é crucial à sua sobrevivência em um mercado cada vez mais competitivo.

De acordo com o SEBRAE (Serviço Brasileiro de Apoio às Micro e Pequenas Empresas), em relatório realizado no ano de 2016, referente à última década, as taxas de mortalidade das micro e pequenas empresas chegaram a cerca de $49 \%$ para as empresas com até 2 anos de existência; 31,3\% para as empresas com até 3 anos de existência; e 35,9\% para as empresas com até 4 anos de existência. Dentre os motivos que levam à falência dessas empresas estão a má gestão financeira e falta de capacitação por parte dos empresários.

Apesar de contribuir para a economia do país, as micro e pequenas empresas no Brasil possuíam pouca representatividade e perdiam espaço para as grandes empresas; entretanto, ocorreram mudanças e as pequenas empresas ganharam espaço na economia, a partir de um mercado globalizado, competitivo e exigente de uma praticidade nas organizações para que demandassem custos menores e agilidade, vindo a consolidar empresas de menor porte. Leis foram regulamentadas e implementados programas de incentivo referentes aos empreendimentos de micro e pequeno portes, que contribuíram para uma maior e melhor sistematização deste processo de crescimento neste setor.

A figura 1, adiante, mostra a representatividade dos pequenos negócios, sob diversos prismas. 
Figura 1 - Estatística de Participação dos Pequenos Negócios

\begin{tabular}{|c|c|c|c|}
\hline PARTICIPAÇĀO DOS PEQUENOS NEGOCCIOS NO(A): & ANO & PARTICIPACĀO (\%) & FONTE \\
\hline PIB brasileiro & 2011 & 27,0 & SEBRAE/FGV \\
\hline Nümero de empresas exportadoras & 2014 & 59,4 & FUNCEX \\
\hline Valor das exportações & 2014 & 0,82 & FUNCEX \\
\hline Massa de salários das empresas & 2013 & 41.4 & RAIS \\
\hline Total de empregos com carteira & 2014 & 51,2 & RAIS \\
\hline Total de empresas privadas & 2015 & 98,2 & SEBRAE \\
\hline OUTROS DADOS SOBRE OS PEQUENOS NEGOCCIOS & ANO & TOTAL & FONTE \\
\hline Quantidade de produtores rurais & 2015 & 4,7 milhōes & PNAD CONTINUAA \\
\hline Potenciais empresários com negócio & 2015 & 11,6 milhōes & PNAD CONTINUA \\
\hline Empregados com carteira assinada & 2014 & 19,8 milhöes & RAIS \\
\hline Remuneraçāo média real nas MPE & 2013 & RS $1.485,00$ & RAIS \\
\hline Massa de salário real dos empregados nas MPE & 2013 & RS 24,4 bilhöes & RAIS \\
\hline Número de empresas exportadoras & 2013 & $10,9 \mathrm{mil}$ & FUNCEX \\
\hline Valor total das exportaçōes (US\$ bi FOB) & 2014 & US\$ 2 bilhōes & FUNCEX \\
\hline Valor médio exportado (US\$ mil FOB) & 2014 & US\$ $179,4 \mathrm{mil}$ & FUNCEX \\
\hline
\end{tabular}

Fonte: SEBRAE (2016)

A seguir, a figura 2 revela a evolução das taxas de sobrevivência e mortalidade das MPE com até dois anos de existência.

Figura 2 - Taxa de sobrevivência e mortalidade da MPEs

GRÁFICO 1 - TAXA DE SOBREVIVÊNCIA DE EMPRESAS DE 2 ANOS, NO BRASIL

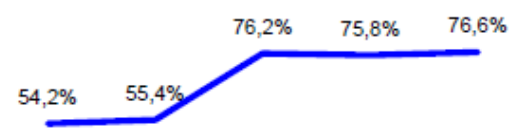

$\begin{array}{llll}2008 & 2009 & 2010 & 2011 \\ \text { Ano de Constituição da Empresa }\end{array}$

GRÁFICO 2 - TAXA DE MORTALIDADE DE EMPRESAS DE 2 ANOS, NO BRASIL

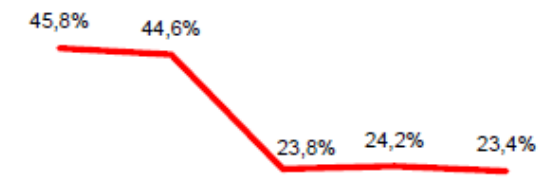

$2008 \quad 2009 \quad 2010 \quad 2011 \quad 2012$

Fonte: SEBRAE (2016)

Assim, este trabalho visa responder a seguinte pergunta: como a Gestão Financeira pode ajudar na perenidade das Micro e Pequenas empresas?

\subsection{Sobre as Micro e Pequenas Empresas}

A Lei Geral das Microempresas e Empresas de Pequeno Porte foi instituída em 2006 para regulamentar o disposto na Constituição Brasileira, que prevê o tratamento diferenciado e favorecido à microempresa e à empresa de pequeno porte. Através da Lei Geral, foi instituído o regime tributário específico 
para os pequenos negócios, com redução da carga de impostos e simplificação dos processos de cálculo e recolhimento, que é o Simples Nacional.

Além disto, a Lei prevê benefícios para as pequenas empresas em diversos aspectos do dia a dia, como a simplificação e desburocratização, as facilidades para acesso ao mercado, ao crédito e à justiça, o estímulo à inovação e à exportação.

A microempresa será a sociedade empresária, a sociedade simples, a empresa individual de responsabilidade limitada e o empresário, devidamente registrados nos órgãos competentes, que aufiram em cada ano calendário a receita bruta igual ou inferior a $R \$ 3.600 .000,00$ (a partir de 2018, este limite aumentará para $\mathrm{R} \$ 4.800 .000,00)$.

Se a receita bruta anual for superior a $\mathrm{R} \$ 360.000,00$ e igual ou inferior a $\mathrm{R} \$ 3.600 .000,00$, a sociedade será enquadrada como empresa de pequeno porte. Estes valores referem-se a receitas obtidas no mercado nacional. A empresa de pequeno porte não perderá o seu enquadramento se obtiver adicionais de receitas de exportação, até o limite de $R \$ 3.600 .000,00$ (SEBRAE, 2016).

A Lei Geral também criou o microempreendedor individual, que é pessoa que trabalha por conta própria e se legaliza como pequeno empresário optante pelo Simples Nacional, com receita bruta anual de até $R \$ 60.000,00$. O microempreendedor pode possuir um único empregado e não pode ser sócio ou titular de outra empresa (SEBRAE, 2016).

\subsection{Caracterização do Problema}

No desenvolvimento do presente trabalho, tenta-se observar e identificar a melhor forma de gerir os recursos da empresa baseada na administração financeira, que será a ferramenta fundamental para traçar metas e definir objetivos para minimizar ao máximo as margens de erro.

Ao observar como são executados e geridos os procedimentos de administração financeira, a organização poderá formatar os processos de todas as atividades onde são investidos os recursos financeiros que dão suporte a toda cadeia de execução dos serviços ou entrega de produto final.

A globalização traz dinamismo aos negócios, fazendo com que um controle mais rígido das finanças através de planilhas de cálculos financeiros, controle de estoques, formação de preços e controles de gastos com materiais, além da análise e interpretação de demonstrativos contábeis, seja eficaz. 


\subsection{A Justificativa do Trabalho}

A elaboração deste trabalho levou em conta a importância da gestão financeira na rotina de qualquer empresa que pretende ser perene e visa à expansão no seu campo de atuação. Durante a execução deste trabalho serão analisados os processos e as ferramentas que a empresa utiliza na sua parte financeira, visando detectar possíveis falhas de procedimentos e usos indevidos de recursos e/ou análises equivocadas de índices ou números apresentados em relatórios diversos.

\subsection{A Relevância do Trabalho}

As constantes mudanças nos mercados de serviços e produtos fazem com que as empresas tenham que acompanhar o surgimento de novas tendências para se manterem competitivas e garantirem seus espaços no cenário econômico. Diante disso, a firma deverá realizar uma boa administração financeira para dar suporte às necessidades dos procedimentos da atividade que executa. A solidez da sua administração a embasará para que esta tenha seu ciclo de vida estendido, bem como gere resultados objetivando uma possível expansão.

\subsection{Objetivo do Estudo}

A importância deste trabalho reside em mostrar aos microempreendedores a importância da Gestão Financeira para o crescimento e desenvolvimento da sua empresa, mudando a cultura e passando a compreender que o planejamento financeiro traz um melhor controle dos resultados que a sua empresa obterá.

Após a inclusão da Gestão Financeira nas MPEs, os microempreendedores passam a ter melhor controle sobre suas empresas, adicionando planejamentos no seu cotidiano e obtendo resultados positivos, levando ao crescimento da economia e ajudando no desenvolvimento do Brasil e, como consequência, diminuindo o índice de mortalidade.

O ponto inicial para análise é determinado pela pergunta problema, que embasa o levantamento de questões, tais como quais são as vantagens e melhorias que podem ser alcançadas para este estudo de caso. Neste sentido, o conjunto de operações administrativas e operacionais terá o suporte da área financeira, que determinará quantitativamente a melhor alocação e o uso dos 
recursos financeiros advindos das operações - mais especificamente, viabilizará uma administração financeira sólida e holística.

Uma correta administração financeira permite que se visualize a atual situação da empresa. Registros adequados permitem análises e colaboram com o planejamento, a superação de problemas e a otimização de resultados.

Uma boa gestão financeira atua através de um conjunto de ações e procedimentos administrativos, que envolvem o planejamento, a análise e 0 controle das atividades financeiras da empresa.

Para atingir o objetivo principal deste trabalho, desenvolveram-se os seguintes objetivos secundários:

a) Análise dos pontos relevantes do controle financeiro;

b) Identificação das falhas na administração financeira; e

c) Verificação da necessidade de novos métodos e análises a serem implementados para um melhor controle administrativo.

São trabalhadas competências e conteúdos como:

- Conhecer as principais formas de controle, planejamento e análise necessárias à organização das finanças em uma empresa, para controle de todas as atividades financeiras que possam assegurar bons resultados;

- Compreender a necessidade de uma administração minuciosa das atividades financeiras como garantia de permanência no mercado e redução dos riscos financeiros; e

- Levantar, documentar e analisar todas as informações financeiras de uma empresa para tomar decisões acertadas, refletindo sobre os riscos que podem ocorrer nas finanças daqueles que possuem uma má gestão em sua empresa.

\subsection{Delimitação do Estudo}

Os questionários deste trabalho foram direcionados aos três donos da empresa UCL Refrigeração Ltda, o que pode trazer limitações ao estudo e algum viés nas estatísticas aqui utilizadas.

No mais, este estudo delimitou-se a colher informações em dados secundários setoriais e textos acadêmicos sobre a importância do conhecimento 
da gestão financeira, em que a capacitação dos gestores e empreendedores é determinante fator de influência na diminuição da mortalidade precoce das micro e pequenas empresas no Brasil.

Para isto, teve como referência o relatório de Sobrevivência das Empresas no Brasil, datado de outubro/2016, feito pelo Serviço Brasileiro de Apoio ás Micro e Pequenas Empresas - SEBRAE Nacional, além do tema: "Capacitação", da Secretaria Especial da Micro e Pequena Empresa Presidência da República / 2013.

A figura 3, abaixo, apresenta tópicos comumente analisados pelo SEBRAE para elaborar o perfil do empreendedor das MPE.

Figura 3 - Perfil do empreendedor nas MPEs

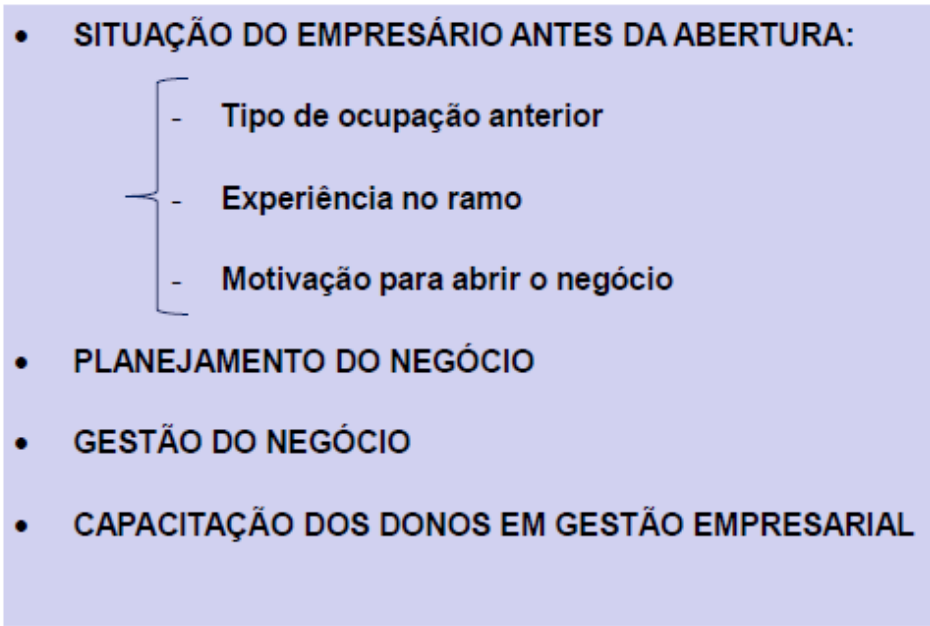

Fonte: SEBRAE (2016)

Segundo o SEBRAE (2016), a ocupação anterior da maioria dos microempresários era de empregado formal, seguido de empreendedor informal, empregado informal e dono de casa.

Quando questionados acerca da motivação que os levou a se tornar um empreendedor, citaram a vontade de ser independente, de não ter um chefe e a necessidade de uma fonte de renda.

Embora muitos tenham alguma ou até bastante experiência no ramo, sem conhecimento em administração, o empresário corre o risco de falir em pouco tempo. Poucos são os empreendedores que fazem um Plano de Negócios 
completo, uma pesquisa de mercado ou qualquer outro estudo mais aprofundado.

Ademais, sem a experiência administrativa (teórica e prática) para a gestão do negócio e a respectiva capacitação prévia em gestão empresarial, o sucesso e perenidade do negócio ficam seriamente comprometidos. 


\section{Referencial Teórico}

O estudo da importância da Gestão Financeira nas MPEs visa demonstrar que os principais fatores que causam a mortalidade precoce estão relacionados à má gestão de finanças, tendo como itens a falta de competências para lidar com os juros e impostos do mercado, bem como o precário gerenciamento de receitas e despesas, fluxo de caixa, capital de giro, dentre outros (REMIPE - Revista de Micro e Pequenas Empresas e Empreendedorismo da FATEC Osasco - V.1, no 1, jan-jun. 2015).

\subsection{Situação geral das MPE e o papel do planejamento}

Através de estudo recente realizado pelo Serviço Brasileiro de Apoio à Micro e Pequenas Empresas (2016), os percentuais de sobrevivência das empresas com até 2 anos de atividade no país estão aumentando. Conforme a pesquisa, as taxas de sobrevivência eram de $76,2 \%$ para empresas criadas em 2010, de 75,8\% para as criadas em 2011 e de 76,6\% para as surgidas em 2012. Em relação às regiões do país, em 2012 o Sudeste estava com 78,0\% de taxa de sobrevivência de empresas com até 2 anos de atividade, acima da média nacional, de 76,6\%. Já em relação aos estados, o Rio de Janeiro figurava com $80,0 \%$ de taxa de sobrevivência, também acima da média nacional, e superando, inclusive, a região Sudeste (78,0\%) e o estado de São Paulo, que tinha 76,0\%.

Pode-se dizer que o planejamento tem seu significado literal no ato ou efeito de planejar, ação de preparação para qualquer empreendimento, conforme regras e métodos determinados; planificação, processo que leva ao estabelecimento de um conjunto coordenado de ações (por empresas, pessoas, governo etc.), visando atingir determinados objetivos; elaboração de planos ou programas governamentais, especialmente na área econômica e social.

Já na abordagem financeira se relaciona às finanças, à circulação e gestão de recursos financeiros e de outros recursos disponibilizados.

Contudo, o conceito administrativo de planejamento financeiro faz a junção desses dois enfoques levados para um plano empresarial.

No atual cenário econômico, diversos fatores globais influenciam e deixam vulneráveis as organizações em todos os setores. Diante disso, o plano 
financeiro empresarial tende a ser mais valorizado e apreciado em primeira instância no momento da tomada de decisões. Segundo Gitman (1997, p. 588), "as empresas utilizam-se de planos financeiros para direcionar suas ações, com vistas a atingir seus objetivos imediatos e a longo prazo, onde um grande montante de recursos está envolvido".

\subsection{O Capital de giro}

A principal função do capital de giro é subsidiar e dar continuidade às operações econômicas da empresa, que por sua vez seja usado para aquisições do estoque ou mesmo as despesas geradas no operacional. Ele é composto das contas do ativo e passivo circulante, que, com base na análise destas contas, possibilita a tomada de decisões em termos financeiros sempre a curto prazo, evitando a falência financeira (Portal BRASIL ESCOLA - 2017).

O fluxo de caixa termina por ser de vital importância para que as finanças se mantenham, pois é a administração que controla as entradas e saídas do caixa. Com isso, é possível determinar em que investir no curto prazo. Desse modo, os créditos e as contas a receber tornam-se o ponto chave para se planejar, organizar, controlar e dirigir as políticas de análise dos créditos, que posteriormente serão repassados aos clientes no curto prazo, para que assim o dinheiro gire no caixa nesse período e possibilite novos investimentos no mesmo prazo (Portal BRASIL ESCOLA -2017).

Logo, a administração do capital de giro resulta em uma administração adequada das contas que contém. As contas a receber se originam a partir de políticas de marketing, que por sua vez possibilitam as vendas e se transformam em dinheiro no curto prazo, para que os produtos não fiquem estagnados em seu estoque. $O$ endividamento ocorre pela falta de atenção e má administração deste recurso (Portal BRASIL ESCOLA - 2017).

\subsection{A Empresa analisada}

A UCL Refrigeração Ltda. surgiu da ideia de levar ao mercado soluções inovadoras e, ao mesmo tempo, de baixo custo de implementação e operação nas instalações, manutenções de ar condicionado e geladeiras. Neste sentido, a empresa foi criada com o conceito de empresa inovadora, com o compromisso de fornecer serviços e soluções de instalação, manutenção e consertos com alto padrão de qualidade, sendo realizados por profissionais especializados, visando 
sempre a redução de custos, entrega no prazo e com capacidade de atender não somente às especificações dos clientes, como também às normas e regulamentos praticados pelo setor.

Estabelecida em 2015 com sede no Rio de Janeiro, a empresa é voltada principalmente para as áreas de ventilação, ar condicionado e refrigeração em geral. Desta forma, vem desenvolvendo soluções completas desde a concepção de sistemas de ares-condicionados, passando pelo sistema elétrico, fornecendo equipamentos, realizando instalação dos mesmos e, por fim, realizando a manutenção, sempre objetivando a redução de custos, eficiência energética e facilidade de operação - atendendo, assim, aos setores comercial e residencial.

A empresa utiliza ferramentas e mão de obra qualificada com técnicas de gerenciamento e gestão de projetos, gestão de custos, a fim de agregar valor ao empreendimento dos clientes, tendo como principais compromissos:

- Elaborar e executar projetos de instalação, minimizando custos;

- Focar no acompanhamento periódico de manutenções preventivas;

- Buscar a inovação tecnológica de suas ferramentas e práticas; e

- Atender a clientes residenciais e empresas de pequeno e médio portes.

\subsection{A Administração Financeira}

Segundo Assaf Neto (2002), "a administração financeira é um campo de estudo teórico e prático que objetiva, essencialmente, assegurar um melhor e mais eficiente processo de captação e alocação de recursos de capital".

Segundo Gitman (2004), as atividades do administrador financeiro devem ser realizadas de modo que atinjam os objetivos dos acionistas. O objetivo mais citado é o da maximização do lucro, ou seja, o administrador financeiro deve tomar decisões que tragam maior retorno aos acionistas.

É necessário compreender o sentido e o que significam as finanças de uma empresa, sendo estas um conjunto de recursos disponíveis circulantes que serão usados em transações e negócios com transferência e circulação de valores em espécie. Também é necessária a análise da situação econômica da empresa, com relação ao seu patrimônio.

Desta forma, fica evidenciado que as finanças fazem parte do cotidiano no controle dos recursos para compras e aquisições, tal como no gerenciamento 
da empresa, suas respectivas áreas, seja no marketing, na produção, na contabilidade e, principalmente, no planejamento de nível estratégico, gerencial e operacional, em que se utilizam dados e informações financeiras para as tomadas de decisão da empresa.

\subsubsection{Ferramentas da Administração Financeira - Fluxo de Caixa}

"Podemos definir o fluxo de caixa como a sintetização dos movimentos monetários realizados por uma empresa em um determinado período, bem como o registro de despesas e receitas" (UNAR (ISSN 1982-4920), Araras (SP), v. 5, n. 1 , p. $51-58,2011)$.

Cada empresa tem sua especificidade, sendo assim, os fluxos monetários são diferentes, tendo cada empresa que se adaptar ao modelo de fluxo de caixa da própria empresa, não admitindo "importação de modelos". Por esse motivo é importante que o gestor financeiro tenha conhecimento de todo o ciclo financeiro da empresa, suas receitas e suas despesas, para melhor formatação do fluxo de caixa.

Uma das principais metas financeiras das empresas é operar com baixos custos e alta rentabilidade. Desta maneira, não deve haver indecisões sobre o que fazer com seus recursos financeiros, principalmente no curto prazo. O fluxo de caixa permite-nos diagnosticar possíveis períodos onde ocorrerão excedentes ou escassez de caixa, auxiliando o gestor a tomar as medidas necessárias para prevenir tais ocorrências.

Com relação ao período de tempo analisado em um fluxo de caixa, depende de a empresa decidir qual vai atender às suas reais necessidades, desde diariamente até anualmente. Esta ferramenta financeira é de extrema importância para todas as empresas, independente de seu mercado e seu patamar. Ela auxilia os gestores financeiros a solucionar as dificuldades econômicas, e também sobre como administrar melhor os recursos disponíveis. 
Tabela 1 - Exemplo de Controle de Caixa - Criação do Autor

\begin{tabular}{|c|c|c|c|c|c|c|}
\hline \multicolumn{7}{|c|}{ CONTROLE DIÁRIO DE CAIXA } \\
\hline DATA & IDENTIICAÇÃO & DESCRIÇÃO & ENTRADAS & SAÍDAS & & ALDO \\
\hline $01 / 10 / 2015$ & SALDO INICIAL & & & & $\mathrm{R} \$$ & $2.000,00$ \\
\hline $01 / 10 / 2015$ & DONA MARIA DA SILVA & SALÁRIO DO MÊS & & 32,00 & RS & $1.968,00$ \\
\hline $01 / 10 / 2015$ & SEU CHICO MARTINS & SERVIÇOS DE FACHINA DA LOJA & & 353,33 & RS & $1.614,67$ \\
\hline 01/10/2015 & EMPRESA FULANA & ENERGIA ELÉTRICA DE SETEMBRO & & 39,42 & RS & $1.575,25$ \\
\hline 01/10/2015 & SUPERMERCADO AMIGO DOS OUTROS & PÃES PARA LANCHES DA TARDE & & 181,92 & RS & $1.393,33$ \\
\hline $01 / 10 / 2015$ & DONA GERALDA DA SILVA & VENDA DE PRODUTO A & 15,00 & & RȘ & $1.408,33$ \\
\hline 01/10/2015 & SEU FRANCISCO DA ESQUINA PINTO & PRESTAÇÃO 3 DA COMPRA 3 & 350,00 & & $R S$ & $1.758,33$ \\
\hline \multicolumn{5}{|r|}{ SALTO DO CAIXA } & $R S$ & $1.758,33$ \\
\hline
\end{tabular}

\subsubsection{Ferramentas da Administração Financeira - DRE}

Em um primeiro momento, entende-se que o DRE é uma simples ferramenta da contabilidade, entretanto ela é fundamental para a gestão financeira, uma vez que, através dela, avaliamos se a empresa obteve lucro ou prejuízo.

A Demonstração do Resultado do Exercício é uma demonstração contábil que apresenta o fluxo de receitas e despesas, que resulta em aumento ou redução do patrimônio líquido ente duas datas (HOJl, 2009).

"Ela deve ser apresentada de forma dedutiva, isto é, inicia-se com a Receita operacional bruta e dela deduzem-se custos e despesas, para apurar o lucro líquido" [...] (HOJI, 2009, p.267). É importante salientar que se o gestor financeiro estiver atento a essa informação crucial, este poderá evitar prejuízos. 
Tabela 2 - Modelo DRE - Portal Contábeis 2017

\begin{tabular}{|l|c|c|c|}
\hline DEMONSTRAÇÃO DO RESULTADO DO EXERCíCIO & Valores em RS & FÓRMULA & $\begin{array}{l}\text { Lin } \\
\text { ha }\end{array}$ \\
\hline Receita Bruta & & (A) \\
(-) Impostos Incidentes sobre a venda & & (B) \\
(=) Receita Liquida & C=a-b & (C) \\
\hline (-) Custo das Mercadorias Vendidas - CMV & & (D) \\
\hline (=) LUCRO BRUTO & E=C-d & (E) \\
\hline (-) DESPESAS OPERACIONAIS & F= (g+h+j)-i & (F) \\
\hline (-) Despesas com Vendas & & (G) \\
\hline (-) Despesas Financeiras & & (H) \\
\hline (+) Receitas Financeiras & $($ I) \\
\hline (-) Despesas Gerais e Administrativas & & (J) \\
\hline (=) Lucro/Prejuizo Operacional & L=E-f & (L) \\
\hline
\end{tabular}

\subsection{O Planejamento Financeiro}

O planejamento é a base de qualquer empresa que deseja iniciar suas operações, visto que ele determina e orienta quais os caminhos a serem trilhados, com as respectivas coordenação e controle das ações da empresa para atingir os objetivos. O planejamento financeiro deve analisar os diferentes cenários para que a empresa possa escolher a melhor opção para o momento de mercado que ela estiver enfrentando. Para desenvolvê-lo, devem-se manipular os dados projetados, vinculados ao planejamento da empresa, que vão sendo agrupados e proporcionam a geração dos resultados (GITMAN, 2001).

O planejamento é dependente da obtenção de recursos, tais como informações, conhecimento de mercado e financeiros, que podem ser de curto ou longo prazos. A eficiente administração dos recursos pode gerar um melhor controle da produção, que resultará em atingir a geração de resultados objetivada.

Visto desta forma, a administração é a função primordial em uma empresa. E o planejamento é o começo de tudo. 
A esquematização de um planejamento deve partir da elaboração de um plano estratégico. A base será um determinado período de tempo, que ditará os parâmetros que refletirão nos planos e orçamentos diários. Geralmente, os planejamentos de curto prazo servem de paradigmas para atingir os objetivos da organização a longo prazo. Já no planejamento de longo prazo, pode-se prever o impacto antecipado da implementação de ações que minimizarão impactos na saúde financeira da empresa.

Conforme Zdanowicz (2000), o sistema de planejamento financeiro e de orçamentos utiliza técnicas de projeções para orientar a empresa no processo de tomada de decisão, e enfatiza que as decisões têm tendência a serem eficazes, quando embasadas nos planejamentos e controles financeiros.

De acordo com Gitman (2001), o bom planejamento se inicia com planos financeiros ou estratégicos de longo prazo, que servirão de base para planos operacionais e orçamentos de curto prazo. Os planejamentos de longo prazo incorporam as ações financeiras e o impacto destas ações no intervalo entre dois a dez anos.

\subsection{A Gestão das Pequenas e Médias Empresas}

As pequenas e médias empresas possuem características próprias que podem representar uma vantagem ou uma desvantagem no cenário onde atuam. Estas firmas causam impacto tanto em sua forma de organização interna, como em sua articulação com os clientes, fornecedores, instituições governamentais e demais atores do seu entorno (SEBRAE, 2016).

Isto Ihes confere uma atuação diferenciada em relação às grandes empresas, possuindo uma estrutura organizacional simples com pouca formalização e centralização da gestão na pessoa do dono e/ou sócios, onde as tomadas de decisão são baseadas na experiência, no julgamento ou intuição destes.

Algumas dessas características, como estrutura organizacional simples, pouca burocracia, rapidez de resposta, flexibilidade, dentre outras, são identificáveis como altamente desejáveis, tendo em vista, que propiciam uma reação mais rápida em um cenário onde as mudanças são constantes e céleres. Entretanto, características como recursos humanos e financeiros reduzidos são obstáculos ao desenvolvimento das pequenas e médias empresas. 
Adicionalmente, com o perfil conservador e individualista, este empreendedor mostra que a falta de planejamento de médio e longo prazos se faz presente, já que o proprietário gerencia seu negócio preocupando-se com o curto prazo, e não tendo a consciência da perda de competitividade daí decorrente. 


\section{Metodologia}

O presente trabalho é tipificado como científico, no qual os dados foram coletados por meio do método da pesquisa bibliográfica na área de planejamento e gestão financeira, em livros específicos da área, artigos postados na Internet, entrevistas com os administradores do negócio e site do SEBRAE.

Pretendeu-se mostrar através do presente trabalho que, por ausência de planejamento, a continuidade das micro e pequenas empresas é fatalmente prejudicada. Apresentou-se ainda como a ferramenta da gestão administrativa, por mínima que seja a sua aplicação, aqui restringida à gestão financeira, pode contribuir para a manutenção da continuidade das micro e pequenas empresa no Brasil.

A dinâmica do presente trabalho foi baseada em entrevistas com 7 (sete) perguntas fechadas dirigidas aos três sócios-administradores, com apresentação dos demonstrativos financeiros e suas utilidades em como mensurar a parte financeira da empresa.

A partir das respostas, foram feitas análises e quantificadas percentualmente, gerando os resultados apresentados ao longo do capítulo 4 .

Para avaliar o desempenho de uma MPE, podem ser utilizadas diferentes medidas. Entretanto, a escolha de tais medidas pode ser limitada às informações disponíveis nesse tipo de empresa, haja vista que muitas informações não são registradas, dificultando assim a medição do desempenho do negócio. Estudos sobre o desempenho das MPEs vêm sendo desenvolvidos por diferentes pesquisadores, conforme demonstra o quadro abaixo:

Tabela 3 - Estudos envolvendo medidas de desempenho das MPEs

\begin{tabular}{|c|l|}
\hline Medidas de desempenho utilizadas & Autor (es) \\
\hline Indicadores relacionados à estratégia de & Molina; Medina (2003) \\
negócios e aos aspectos financeiros, tais como: & \\
lucro bruto, valor adicionado por empregado. & \\
Indicadores relacionados às práticas de uma & \\
\hline
\end{tabular}




\begin{tabular}{|c|c|}
\hline $\begin{array}{l}\text { empresa, como horas de inspeção do trabalho em } \\
\text { percentagem do total de horas trabalhadas. } \\
\text { Indicadores relacionados aos fatores tangíveis da } \\
\text { empresa. Por exemplo, taxa de desperdício devido } \\
\text { a erros. }\end{array}$ & \\
\hline $\begin{array}{l}\text { Indicadores ambientais: consumo total em } \\
\text { relação ao total produzido, eficiência no uso da } \\
\text { matéria-prima, consumo de embalagem em } \\
\text { relação ao total produzido, materiais perigosos } \\
\text { utilizados em relação aos materiais totais, } \\
\text { consumo de energia em relação ao total } \\
\text { produzido, consumo de água em relação ao total } \\
\text { produzido, resíduos em relação ao total produzido, } \\
\text { reciclagem do resíduo em relação ao total de } \\
\text { resíduos, consumo de água em relação ao total } \\
\text { produzido. }\end{array}$ & $\begin{array}{l}\text { Rao et al. (2006); Rao et } \\
\text { al. (2009) }\end{array}$ \\
\hline $\begin{array}{l}\text { Método de avaliação semi-quantitativo para } \\
\text { estimar o nível de absorção da produção mais } \\
\text { limpa praticada pelas pequenas empresas. }\end{array}$ & $\begin{array}{l}\text { Howgrave-graham; } \\
\text { Berkel (2007) }\end{array}$ \\
\hline $\begin{array}{l}\text { Indicadores não financeiros e não físicos } \\
\text { relacionados com a aquisição, mensuração e } \\
\text { monitoramento do capital intelectual da empresa. }\end{array}$ & $\begin{array}{l}\text { Jussupova-Mariethoz; } \\
\text { Probst (2007) }\end{array}$ \\
\hline $\begin{array}{l}\text { Indicador agregado para o planejamento } \\
\text { estratégico formado por sete medidas que } \\
\text { representam cada componente do processo de } \\
\text { planejamento estratégico: missão, objetivos, } \\
\text { análise interna e externa, seleção da alternativa } \\
\text { estratégica, implementação, controle e avaliação. } \\
\text { Indicador agregado de desempenho global } \\
\text { composto por: nível de realização dos objetivos, } \\
\text { rotatividade de funcionários, dinâmica de volume }\end{array}$ & Gică; Negrusa (2011) \\
\hline
\end{tabular}


\begin{tabular}{|l|r|r|}
\hline $\begin{array}{l}\text { de negócios, nível de desempenho observado no } \\
\text { ano atual em comparação com o ano anterior. }\end{array}$ & \\
\hline Indicadores utilizados na produção em & Spath (2011) \\
sistemas enxutos, os quais fazem parte de um & \\
método de planejamento híbrido para a produção \\
enxuta em pequenas empresas.
\end{tabular}

Fonte: Autores citados neste Quadro

A metodologia adotada será a de pesquisa bibliográfica, dados secundários e entrevista com os administradores do negócio, listando itens como conceito de gestão financeira e principais funções dentro da empresa.

A identificação das ferramentas irá auxiliar no trabalho do gestor face aos novos desafios que se impõem, oriundos da forte globalização econômicofinanceira e da competitividade das empresas.

O conceito e o histórico da gestão financeira, bem como as principais funções e os problemas que a firma pode enfrentar, serão abordados neste estudo. 
Acredita-se no sucesso de uma empresa quando o gestor financeiro possui o devido conhecimento e acesso às ferramentas que otimizam suas tomadas de decisão. 


\section{Apresentação e análise dos resultados}

O sucesso ou fracasso nos negócios de uma empresa são determinados por diversos fatores, dentre eles o financeiro, onde, segundo Gitman (1997), o planejamento financeiro é um instrumento utilizado para direcionar as ações, de modo que os objetivos a curto e longo prazo sejam alcançados.

\subsection{O modelo de administração utilizado}

A pesquisa em questão buscou elencar as práticas de gestão financeira adotadas pela UCL Refrigeração Ltda. - enquadrada como micro e pequena empresa na cidade do Rio de Janeiro-RJ, na qual foram respondidos questionários com perguntas sobre o perfil dos seus gestores, a utilização de demonstrativos contábeis para as tomadas de decisões, as práticas utilizadas na gestão de custos e também a respeito das práticas utilizadas na gestão de capital de giro da empresa.

\subsection{Análise dos resultados}

Em busca de uma base para análise sobre o perfil dos gestoresempreendedores, sua formação e/ou conhecimento na área financeira, foram formuladas perguntas nas quais foram englobados itens de relevância como:

- Capacitação na área financeira;

- Grau de instrução;

- Conhecimento e/ou utilização de relatórios contábeis; e

- Análise de custos e precificação de produtos e/ou serviços.

A primeira pergunta foi: "de quem é a responsabilidade pela gestão financeira da empresa"?

A tabela 4, abaixo, mostra os resultados. 


\section{Tabela 4 - Análise da Responsabilidade pela Gestão Financeira}

\begin{tabular}{|l|r|r|}
\hline \multicolumn{3}{|c|}{ Responsável pela Gestão financeira da Empresa } \\
\hline \multicolumn{1}{|c|}{ Responsável } & Quantidade & \multicolumn{1}{|c|}{$\%$} \\
\hline $\begin{array}{l}\text { Proprietários/sócios que possuem capacitação na área } \\
\text { financeira }\end{array}$ & 1 & $33 \%$ \\
\hline $\begin{array}{l}\text { Proprietários/sócios que não possuem capacitação na área } \\
\text { financeira }\end{array}$ & 2 & $67 \%$ \\
\hline Total & 3 & $100 \%$ \\
\hline
\end{tabular}

Fonte: Dados Empresa - pesquisa 2016

Com base nos resultados, pode-se verificar que $2 / 3$ dos gestores financeiros são os donos empreendedores ou sócios que não possuem conhecimento na área financeira. Esses dados confirmam o que já é ratificado em várias publicações, dentre as quais se pode citar o "14ํㅜ Fórum de Boas Práticas" da Fundação Nacional da Qualidade (FNQ), que desenvolve estas publicações desde junho de 2014 sobre as micro e pequenas empresas, que possuem como característica principal uma estrutura empresarial consolidada, porém marcada pela falta de visão e planejamento de médio e longo prazos.

Além disso, no caso dos conhecimentos técnicos, o proprietário e/ou sócios respondem por quase todas as áreas da empresa, pois normalmente são advindos de outras áreas da economia, ou mesmo obtiveram capital e resolveram investir em algo que creem ser rentável e perene.

\subsection{Grau de Instrução dos Responsáveis Financeiros}

No que se refere ao grau de instrução, os resultados da tabela 5 corroboram o perfil pré-conceituado do empreendedor, pois $2 / 3$ dos gestores não completaram o ensino médio, ou seja, limitaram-se em praticamente realizar as operações matemáticas fundamentais. O nível de escolaridade pode comprometer a capacidade do empreendedor em absorver e interpretar melhor as informações de mercado, não dando ênfase a um gerenciamento mais eficaz.

Foi observado também que $100 \%$ dos gestores não possuem sequer ensino superior completo, dentre estes o percentual de $33 \%$ que corresponde a um dos sócios que demonstra uma melhor capacidade de entendimento na área financeira, mas não com a devida profundidade e habilidade de análise, mostrando a fragilidade dessas empresas perante o mercado em que atuam, e 
diante da falta de conhecimento técnico necessário para uma melhor gestão dos negócios e possível crescimento no mercado.

Tabela 5 - Resultado Análise Composição do Grau de Instrução

\begin{tabular}{|l|r|r|}
\hline \multicolumn{2}{|c|}{ Qual do grau de instrução do administrador financeiro da empresa } \\
\hline \multicolumn{1}{|c|}{ Responsável } & Quantidade & \multicolumn{1}{c|}{$\%$} \\
\hline Fundamental completo & 0 & $0 \%$ \\
\hline Médio Incompleto & 2 & $67 \%$ \\
\hline Médio completo & 0 & $0 \%$ \\
\hline Superior incompleto & 1 & $33 \%$ \\
\hline Superior completo & 0 & $0 \%$ \\
\hline Pós-graduação & 0 & $0 \%$ \\
\hline Total & 3 & $100 \%$ \\
\hline
\end{tabular}

Fonte: Dados Empresa - pesquisa 2016

\subsection{Utilização de Relatórios Contábeis}

No que diz respeito à utilização de relatórios contábeis para a tomada de decisão pelos gestores financeiros da empresa, o questionamento foi realizado da seguinte forma (estatísticas na tabela 6):

"O gestor financeiro utiliza ou tem ciência sobre relatórios contábeis para a tomada de decisões"?

Tabela 6 - Análise Utilização de Relatórios Contábeis

\begin{tabular}{|l|r|r|}
\hline \multicolumn{1}{|c|}{ Tipo de relatório contábil } & Quantidade & \multicolumn{1}{c|}{$\%$} \\
\hline Nenhum & 2 & $67 \%$ \\
\hline Básicos (Balancete, Balanço Patrimonial, DRE, DFC) & 1 & $33 \%$ \\
\hline & & \\
$\begin{array}{l}\text { Complexos (Índices de Atividades, Índices de Rentabilidade } \\
\text { e Lucratividades, Índices de Liquidez, Indicadores de } \\
\text { Endividamento, Ciclo Operacional e Financeiro, VPL, TIR) }\end{array}$ & & \\
\hline Total & & $0 \%$ \\
\hline
\end{tabular}

Fonte: Dados Empresa - pesquisa 2016

Conforme o resultado, 2/3 das pessoas responsáveis pelas tomadas de decisão não utilizam nenhum tipo de relatório contábil como suporte, sendo que 
apenas $1 / 3$ delas utiliza os mais básicos, como o balancete, balanço patrimonial, demonstrativo de resultados do exercício e o demonstrativo de fluxo de caixa, os quais possuem um número reduzido de informações para dar suporte às decisões mais complexas, como melhores formas de financiamento de projetos e de obtenção de linha de crédito mais acessível no mercado, dentre outras.

O conhecimento, saber para o que serve, bem como suas análises são de grande importância, pois fornecem diagnósticos por vários ângulos da empresa, sejam eles financeiros e/ou econômicos, e devem ocorrer periodicamente para que as tomadas de decisão não sejam arbitrárias, e sim pautadas em números mais precisos e bem próximos da realidade da empresa.

\subsection{Gestão de Custos da Empresa x Preço de Venda}

Em relação à gestão de custos, questionamentos foram abordados sobre as técnicas utilizadas pela empresa nas compras de materiais e também na formação do preço de venda dos produtos e/ou serviços, onde foram obtidos os respectivos resultados em números e percentuais, conforme respostas adiante (tabelas 7 e 8). As seguintes perguntas foram feitas:

"Como são geridos os custos em relação às compras efetuadas e de que forma é realizada a formação do preço de venda"?

Tabela 7 - Análise Gestão de Custos

\begin{tabular}{|l|r|r|}
\hline \multicolumn{1}{|c|}{ Gestão de Custos (compras) } & Quantidade & $\%$ \\
\hline $\begin{array}{l}\text { As compras de materiais são realizadas sem pesquisa de } \\
\text { melhores preços no mercado. }\end{array}$ & 2 & $67 \%$ \\
\hline $\begin{array}{l}\text { As compras de materiais são realizadas através de uma } \\
\text { cotação prévia utilizando o mercado local. }\end{array}$ & 1 & $33 \%$ \\
\hline $\begin{array}{l}\text { As compras de materiais são realizadas através de uma } \\
\text { cotação prévia no mercado de modo geral. }\end{array}$ & 0 & $0 \%$ \\
\hline Total & 3 & $100 \%$ \\
\hline
\end{tabular}

Fonte: Dados Empresa - pesquisa 2016 
Tabela 8 - Análise Gestão de Precificação

\begin{tabular}{|l|r|r|}
\hline \multicolumn{1}{|c|}{ Gestão de Custos (preço de venda) } & Quantidade & $\%$ \\
\hline $\begin{array}{l}\text { A média de mercado é parâmetro para a formação do } \\
\text { preço de venda. }\end{array}$ & 2 & $67 \%$ \\
\hline $\begin{array}{l}\text { O preço de venda é calculado a partir do preço adquirido } \\
\text { - imputa-se um percentual sobre. }\end{array}$ & 1 & $33 \%$ \\
\hline $\begin{array}{l}\text { O preço de venda é calculado levando-se em conta os } \\
\text { custos diretos e indiretos do produto. }\end{array}$ & 0 & $0 \%$ \\
\hline Total & 3 & $100 \%$ \\
\hline
\end{tabular}

Fonte: Dados Empresa - pesquisa 2016

Observando as ações nas aquisições de materiais, $67 \%$ dos que comandam não realizam qualquer pesquisa de preço na aquisição, em vista de uma demanda imediata, perdendo, dessa maneira, oportunidades de melhora na margem de ganho de seus produtos e/ou serviços e, até mesmo, uma maior competitividade no mercado. Apenas $33 \%$ se preocupam em realizar pesquisas de preços, mas se limitando à região de atuação.

O atual cenário econômico brasileiro faz com que se tornem fundamentais a gestão, o controle e a redução dos custos nas empresas, para que essas possam se manter competitivas no mercado, tendo como finalidade um maior lucro, a fim de perpetuarem-se no ramo.

No que diz respeito à formação do preço de venda, 67\% dos gestores se utilizam de técnicas limitadas, onde seguem o mercado para fim de precificação, dando pouca diferenciação dos preços da concorrência ou levando em conta o poder aquisitivo do cliente final, dentre outras formas. O restante leva em conta o valor de aquisição desses bens para formarem o preço de venda, atribuindo um percentual tido como ideal sobre esses valores. Essa técnica não deixa de ser arbitrada, já que cada produto possui uma carga tributária diferente, bem como custos com estocagem, armazenagem, transporte e administração diferenciados.

Existem muitas variáveis que fazem a diferença para o sucesso e o fracasso de uma empresa, e uma delas é a formação de preços. A definição de quanto cobrar sobre os produtos e/ou serviços é de grande relevância para o crescimento do negócio. O preço é indicador de avaliação dos clientes, que sinalizam positiva ou negativamente para as ambições da empresa no mercado. Dessa forma, possuir uma estratégia bem postada desde o início é um grande passo para atrair os consumidores, permitindo que a empresa entregue resultados satisfatórios sem correr riscos de entrar em dívidas ou baixar a qualidade do produto e/ou serviço. 


\subsection{Gestão do Capital de Giro}

Com relação ao capital de giro, foram abordados questionamentos sobre as perspectivas das contas a pagar e das contas a receber para os próximos 180 dias de atividades da empresa, onde foram obtidos os respectivos resultados das tabelas 9 e 10, adiante, a partir da seguinte pergunta:

"Há uma gestão direta e minuciosa do capital de giro na empresa que possa vislumbrar o valor das contas a pagar e das contas a receber para os próximos 6 meses"?

Tabela 9- Análise Capital de Giro x Contas a Pagar

\begin{tabular}{|l|r|r|}
\hline \multicolumn{1}{|c|}{ Capital de Giro e Contas a Pagar } & Quantidade & $\%$ \\
\hline $\begin{array}{l}\text { Não mensura e não consegue projetar os gastos da } \\
\text { empresa nos próximos 180 dias. }\end{array}$ & 2 & $67 \%$ \\
\hline $\begin{array}{l}\text { Estima o total, mas não consegue projetar de quanto será } \\
\text { o desembolso da empresa nos próximos 180 dias. }\end{array}$ & 1 & $33 \%$ \\
\hline $\begin{array}{l}\text { Tem o valor total e consegue prever o volume de despesas } \\
\text { a ser pago pela empresa nos próximos 180 dias. }\end{array}$ & 0 & $0 \%$ \\
\hline Total & 3 & $100 \%$ \\
\hline
\end{tabular}

Fonte: Dados Empresa - pesquisa 2016

Tabela 10 - Análise do Capital de Giro x Contas a Receber

\begin{tabular}{|l|r|r|}
\hline \multicolumn{1}{|c|}{ Capital de Giro e Contas a Receber } & Quantidade & $\%$ \\
\hline $\begin{array}{l}\text { Não mensura e não consegue projetar os recebimentos da } \\
\text { empresa nos próximos 180 dias. }\end{array}$ & 2 & $67 \%$ \\
\hline $\begin{array}{l}\text { Estima o total, mas não consegue projetar de quanto será } \\
\text { o que a empresa receberá nos próximos 180 dias . }\end{array}$ & 1 & $33 \%$ \\
\hline $\begin{array}{l}\text { Tem o valor total e consegue prever o volume de entrada } \\
\text { de caixa na empresa nos próximos 180 dias. }\end{array}$ & 0 & $0 \%$ \\
\hline Total & 3 & $100 \%$ \\
\hline
\end{tabular}

Fonte: Dados Empresa - pesquisa 2016

Pode-se verificar que a gestão do capital de giro não é tratada como fator de suma importância pela empresa, não havendo, na maioria dos casos, um fluxo futuro de pagamentos e recebimentos em um período mínimo de 180 dias, utilizado como parâmetro pela pesquisa, haja vista que grandes empresas preveem estes dados em orçamentos anuais, com períodos de 360 dias ou mais.

Do total dos seus gestores, $67 \%$ não sabem o montante total e nem possuem uma projeção de pagamentos e recebimentos futuros, limitando-se em 
projeções diárias ou semanais, demonstrando a fragilidade das mesmas frente a alguma dificuldade financeira futura. Desses administradores, 33\% sabem 0 montante geral de pagamentos a fornecedores ou recebimentos de clientes, porém não possuem uma projeção futura de quando essas receitas ou despesas irão ser realizadas, em um período de 180 dias. E o mais grave, nenhum projeta exatamente de quanto irá dispor de capital de giro no referido período.

O capital de giro é influenciado diretamente pelas insuficiências de caixa, inadimplência e altos custos nos financiamentos de estoque. Isto cria um ambiente crítico que pode vir a comprometer a saúde financeira das empresas com estas características. 


\section{Conclusões}

O objetivo deste trabalho era mostrar como o planejamento financeiro nas MPEs é importante para o desenvolvimento da economia no Brasil, e o objetivo específico era revelar a importância que as micro e pequenas empresas possuem no mercado de trabalho e no campo econômico.

Foi mostrada a importância das MPEs e os resultados positivos que podem ser obtidos através de um conhecimento maior sobre a gestão financeira.

Verificou-se a personalidade dos empreendedores no Brasil, suas características e a importância da informação sobre a gestão financeira para eles.

A empresa analisada pertence ao setor de serviços, com atuação na economia local do município do Rio de Janeiro, e demonstrou fragilidade em relação à sua gestão, principalmente na parte financeira, pois, na maioria dos casos, não há uma preocupação com quesitos administrativos mínimos, como uma gestão de custos adequada e um maior controle do capital de giro.

Contudo, os resultados alcançados não podem ser generalizados, devido ao cenário particular analisado e baixa base amostral, mas demonstram uma sinalização das características do mercado.

Para que essa realidade seja diferente, ações como o investimento em capacitação dos gestores na área administrativa-financeira, melhor utilização dos dados contábeis para tomada de decisões, realização de planejamentos futuros, dentre outras, seriam condições de melhoria da conjuntura atual. Tudo isso corroboraria para um desfecho que combatesse a mortalidade das MPEs.

A pesquisa demonstrou o quanto uma organização pode ser fragilizada por falta de conhecimento da área financeira. Quando esta não consegue mensurar seus custos e alocar seus recursos de forma equitativa, é bem provável que haja comprometimento do não aproveitamento das oportunidades que o mercado apresenta. A arbitrariedade nas tomadas de decisões compromete a saúde financeira das empresas, pois oportunidades não são aproveitadas e erros são cometidos com essa prática. O preparo profissional dos gestores torna-se fundamental para que essas empresas possam crescer e desenvolver suas atividades, pois um aporte de conhecimento em gestão permitiria uma melhor 
organização e controle, direcionando os esforços de maneira a alavancar os negócios, aumentando lucros e minimizando custos e despesas.

A gestão deste perfil de empresa poderia ter uma significativa melhora caso administradores ou contadores fossem contratados, visando a um melhor planejamento, organização e controle, norteando as atividades das mesmas. Inicialmente, esta decisão poderia ser bastante onerosa, já que esses profissionais custam caro para as empresas, mas, a longo prazo, poderia gerar vantagens, alavancando os lucros e contribuindo para sua estabilidade financeira.

Não foi possível mensurar medidas de curto, médio e longo prazos, em vista de que as demonstrações financeiras não foram disponibilizadas, um dos grandes empecilhos para a realização este estudo.

Recomendam-se pesquisas constantes para o setor, a fim de ampliar o estudo das técnicas e dos problemas de gestão financeira em micro e pequenas empresas para as de médio e grande porte, com o intuito de realizar uma comparação, buscando identificar as similaridades e diferenças que possibilitem traçar alternativas de aprimoramento para ambas. 


\section{Referências Bibliográficas}

A Importância da Gestão Financeira nas Empresas. Brasil, 2011. Disponível em: http://revistaunar.com.br/cientifica/documentos/vol5_n1_2011/5_a_importancia_d a_gestao.pdf. Acesso em: 05 de dezembro de 2017.

ASSAF NETO, A.; SILVA, C. A. T. Administração do capital de giro. 3. ed. São Paulo: Atlas, 2002.

ASSAF NETO, Alexandre. Estrutura e Análise de Balanços um enfoque econômico financeiro. 9. ed. São Paulo: Atlas, 2010.

BRASIL. SEBRAE. Caderno Serviço Brasileiro de Apoio às Micro e Pequenas Empresas: Negócio a Negócio, Brasília, 2016.

CARDEAL, Josemeire Dantas. A administração de caixa em empresas de pequeno porte: estudo de casos no setor hoteleiro de Salvador-BA. Dissertação (Mestrado em Administração Estratégica) - Universidade Salvador, Salvador, 2006.

EIDT, Jorge. Gestão de custos em indústrias do setor moveleiro estabelecidas no Oeste de Santa Catarina: um estudo multicasos. 2006. 233f. Dissertação (Mestrado em Ciências Contábeis) - Universidade Regional de Blumenau, Blumenau, 2006.

FERREIRA, Denis. A Gestão Financeira nas empresas. $2^{\underline{a}}$ ed. São Paulo: Atlas, 1999.

GARRISON, Ray H; NOREEN, Eric W. Contabilidade gerencial. Trad. José Luiz Paravato. 9. ed. Rio de Janeiro: LTC, 2001.

GICĂ, O. A.; NEGRUSA, A. L. The impact of strategic planning activities on transylvanian SMEs - An empirical research. Procedia - Social and Behavioral Sciences, v. 24, p. 643-648, 2011.

GITMAN, Lawrence J. Princípios de administração financeira. 7 ed. São Paulo: Harbra, 1997.

GITMAN, Lawrence J. Princípios de administração financeira. 2. ed. Porto Alegre: Bookman, 2001.

HOJI, Masakazu. Administração financeira e orçamentária: matemática financeira aplicada, estratégias financeiras, orçamento empresarial. São Paulo: Atlas, 2009.

HOWGRAVE-GRAHAM, A.; VAN BERKEL, R. Assessment of cleaner production uptake: method develoMPEnt and trial with small businesses in Western Australia. Journal of Cleaner Production, v. 15, n. 8-9, p. 787-797, 2007. 
MOLINA, A.; MEDINA, V. Application of enterprise models and simulation tools for the evaluation of the impact of best manufacturing practices implementation. Annual Reviews in Control, v. 27, n. 2, p. 221-228, 2003.

Portal BRASIL ESCOLA. A importância da administração do capital de giro. Disponível em: <http://m.meuartigo.brasilescola.uol.com.br/administracao/aimportancia-administracao-capital-giro.htm>. Acesso em: 11 de outubro de 2017.

Portal Contábeis. <http://www.contabeis.com.br>

Portal Educação. A Importância da Administração Financeira nas Pequenas e Médias Empresas. Brasil, 2004. Disponível em: $<$ https://www.portaleducacao.com.br/conteudo/artigos/esporte/a-importancia-daadministracao-financeira-nas-pequenas-e-medias-empresas/30946/>. Acesso em: 15 de setembro de 2015.

RAO, P. et al. Environmental indicators for small and medium enterprises in the Philippines: An empirical research. Journal of Cleaner Production, v. 14, n. 5, p. 505- 515, 2006.

ROSS, S. A.; WESTERFIELD, R. W.; JAFFE, J. F. Administração financeira. São Paulo: Atlas, 1995.

ROSS, Stephen, WESTERFIELD, Randolph e JAFFE, Jeffrey. Administração Financeira: Corporate Finance. São Paulo: Atlas, 2002.

SPATH, D. et al. Hybrid planning tool in the adaptive design of lean methods. Hybrides Planungswerkzeug zur adaptiven Auslegung von Lean-Methoden, v. 106, n. 6, p. 413-417, 2011.

TIDOR, A. et al. Diagnosing Organizational Culture for SME Performance. Procedia Economics and Finance, v. 3, n. 0, p. 710-715, 2012.

ZDANOWICZ, Jose Eduardo. Fluxo de Caixa: uma decisão de planejamento e controles financeiros 8 ed. Porto Alegre: Sagra Luzzato, 2000. 